\title{
The Luck of the Draw: A Programmatic Description of a Game Designed to Promote Student Engagement and Critical Thinking Skills
}

\author{
Alicia Bower1, Kami L. Tsai', Carey S. Ryan'1, Rebecca Anderson², Andrew Jameton², and Maurice Godfrey³ \\ ${ }^{1}$ Department of Psychology, University of Nebraska-Omaha, Omaha, Nebraska; ${ }^{2}$ Department of Health Promotion, College of Public Health, University of Nebraska \\ Medical Center, Omaha, Nebraska; ${ }^{3}$ Munroe Meyer Institute, University of Nebraska Medical Center, Omaha, Nebraska \\ Keywords: Genetics, STEM engagement, critical thinking skills \\ Publication Date: January 27, 2018 \\ DOI: https://doi.org/10.15695/jstem/v111.8
}

\begin{abstract}
We describe a game and teachers' experiences using it in their middle and high school science courses. The game, which is called "Luck of the Draw", was designed originally to engage medical students and later adopted for middle school, high school, and college students in genetics, and to encourage critical thinking about is-sues such as genetic engineering. We introduced the game to high school science teachers attending a summer workshop and asked them to describe their initial impressions of the game and how they might use it in their classes. We also asked middle and high school students about their experiences playing the game. Results indicated that teachers and students enjoyed the game and identified positive outcomes, including greater engagement and critical thinking. Further, the few potential problems that teachers initially thought might be encountered appeared to occur infrequently; ways to minimize these problems are discussed.
\end{abstract}

\section{INTRODUCTION}

Students typically are eager and enthusiastic to play games, so games can be a great way to engage students in science. We have developed and evaluated a card game called Luck of the Draw to promote student engagement. The game, which may be adapted to fit specific educational goals, facilitates classroom discussion about the ethical issues involved in the development and application of genetics knowledge. It has been used by teachers in middle school, high school, college, and medical school.

Research indicates that the use of active learner-centered classroom activities yields favorable out-comes (Derting and Ebert-May, 2010; Knight and Wood, 2005). Luck of the Draw is one such activity. Research further indicates that games, in particular, increase students' curiosity (Alden, 2005), provide opportunities to connect course material to the "real world" (e.g., students may assume roles as scientist or parent), increase interactions with peers and teachers, (Alden, 2005; Annetta et al., 2010), and promote the development of critical thinking skills, for example, by encouraging students to question more. Price and colleagues (2011) have proposed that engaging students in science involves helping them learn to back up claims with evidence, connect what they learn in science to their own communities, and communicate what they learn to others.

\section{PROGRAM DESCRIPTION}

The Luck of the Draw, which is played in small groups of three to seven, consists of blue and yellow cards (Figures with representative cards are available in the supplemental materials section). Each blue card contains a physical or behavioral trait as well as a number (on a 1-10 scale) indicating the degree to which the trait will be expressed in the player's unborn offspring. For instance, a card might list "Diabetes" as the trait with expression between 7 and $8(1=$ no risk; 10 $=$ early $\&$ severe). Some traits are fanciful (viz, sales charm) and others are known genetic conditions (viz, cystic fibrosis). Players are dealt five blue cards each and are then given the opportunity to trade up to three of their blue cards for new ones. Because trading is only allowed to occur one time, players risk getting cards that contain less desirable traits than those they traded. Players are asked to explain to other group members their reasons for choosing to trade or keep the traits they were dealt. In the continuum of expression from "1 to 10 " "10" can be a best or worst case. Thus, the players have to pay attention to each card and where their "off-spring" falls on that scale.

Once players have their final sets of blue cards, each player rolls a die one time. The number on the die multiplied by 10 tells players how many points they have to "purchase" additional traits or modify the expression of traits already 
in their hands. These additional traits are printed on yellow cards, along with number of points the player must have to acquire the traits. Traits may be physical, such as gender or hair color, or behavioral, such as compassion or kindness. The number of points assigned to each trait is based on the desirability of the trait in society, as well as the phenotypic frequency of the trait. Blonde hair, for example, costs more than brown. Players are asked to explain to other group members their reasons for purchasing each trait as a way of initiating discussion about social values (e.g., why some traits are valued more strongly than others), the extent to which the traits are malleable, and the factors that may affect the malleability of the traits, such as the availability of, and access to, effective treatments.

Once players have had the opportunity to "create" their offspring using the blue and yellow cards, each group may be asked to create a single ideal child using only the traits that group members already have. This task typically stimulates further discussion of ethical issues, as group members cannot simply agree to disagree about their individual choices. Groups may be asked to assume the role of a board of directors at an embryo bank, tasked with deter-mining which embryos to market, at what prices, and what will or will not be disclosed about each embryo. Groups may be asked if they would agree to alter any trait (viz, selecting for deafness) or only some traits, or only in a "favorable" direction. At this juncture, the groups or the entire class, may be invited to discuss ethical issues such as prenatal diagnosis; preimplantation diagnosis; genetic engineering (post-birth or pre-birth); genetic enhancement versus amelioration of disability; the potential of genetic technology to exacerbate the disparity between rich and poor; societal allocation of benefits, such as health care and education; duty to self, offspring, family and society in the presence of a serious heritable dis-order; social judgments of worth, and the like. (A teaching guide is included in the supplemental materials section.)

The traits vary markedly in the extent to which their genetic contributions are known. Down syndrome, for example, has a clearly established genetic basis; "business acumen" and "self-confidence" do not. Of course, variation in the strength of the genetic basis provides an opportunity for discussion, research, and the development of critical thinking skills. However, teachers need to ensure that this issue is clearly ad-dressed during the discussion, so that students do not assume a genetic basis is established for all of the traits on the cards.

Other advantages of the game include the instructor's ability to vary the traits on the cards, and the low cost of conducting the exercise. Teachers may wish to omit specific traits that may be problematic for their students, or create new cards to direct the nature of the discussion and research. Creating new yellow or blue cards may allow instructors to expand students' awareness of various genetic disorders or technological advances.

Teachers' views. We shared the game with teachers and students locally, gathering data to evaluate their experiences. In one case, secondary school teachers ( 21 women, 3 men) who participated in a summer workshop for science teachers were introduced to the game. These teachers taught a range of classes including biology, chemistry, anatomy, physiology, child development, health, and health care careers. Fourteen of the teachers taught high school classes; two taught middle school classes; and eight taught both high school and middle school classes.

After teachers played the game themselves, they responded to several open-ended questions. Teachers were asked to identify the name of the course in which they might use the game, the grade level(s) of the students who would participate, and the teaching objectives or goals they would hope to meet by using the game. They also described potential difficulties in using the game with students. Independent judges coded teachers' responses for three general themes: overall impressions of the game, expected benefits, and anticipated difficulties.

Teachers' impressions were generally favorable (see Table 1). More than a third expressed enthusiasm for the game although they were never directly asked to indicate whether they liked the game. Further, although they were directly asked to identify potential difficulties, fewer than half expressed any reservations about using the game. Potential difficulties that were identified tended to focus on the conditions under which teachers would be hesitant to use the game, such as classrooms with students judged to be too young, immature, or lacking in knowledge or experience, or classrooms in which the student com-position might render the game or the resulting discussion too controversial. Although teachers were not asked to indicate the likelihood of these potential difficulties, their responses did not seem to suggest that they expected them to occur frequently.

Every teacher indicated that the game would generate discussions about genetics, ethics, heritability and the fairness of differences in heritability of traits, and genetic engineering. Teachers' responses further suggested that the game would enhance student engagement and increase critical thinking skills. A number of teachers noted that the game would be used to stimulate discussion among students, and that the discussions would concern the ethics involved in genetic research - the types of game-related activities that have been found to be effective in engaging students in science (Alden, 2005; Annetta et al., 2010).

A number of teachers also noted that the game would be helpful in getting students to examine their own values or the values of their own culture, in get-ting students to think, and in getting students to see both the advantages and disadvantages of genetic engineering or testing. In other words, 
Table 1. Frequency of teacher responses about the benefits and potential difficulties of using the game in class

\begin{tabular}{lcc}
\hline Overall Valence & $\mathrm{n}$ & $\%$ \\
\hline Expressed reservations & 10 & 41.67 \\
Expressed enthusiasm & 8 & 33.33 \\
No mention & 6 & 20.83 \\
\hline
\end{tabular}

\begin{tabular}{lcc}
\hline Benefits & & \\
\hline Promotes discussion & 24 & 100 \\
Genetics & 14 & 58.33 \\
Heritability/fairness & 10 & 41.67 \\
Genetic engineering & 7 & 29.17 \\
No elaboration & 5 & 20.83 \\
Promotes critical thinking & 12 & 50 \\
Examine Values & 8 & 66.67 \\
Think & 3 & 25 \\
$\begin{array}{l}\text { Help students see advantages and } \\
\text { disadvantages }\end{array}$ & 1 & 8.33 \\
Promotes engagement & 3 & 12.5 \\
\hline
\end{tabular}

\section{Difficulties}

Specific

Students too young/immature

Controversial/religious objections

Lack of experience/background

Offended/hurt feelings

General

\begin{tabular}{ccc} 
Instructions & 4 & 44.44 \\
Large classes & 3 & 33.33 \\
Distance learning & 2 & 22.22 \\
\hline None & 6 & 25
\end{tabular}

Note. $N=24$. Valence codes were mutually exclusive. Other-wise, the same response could receive multiple codes. Percent-ages for overall valence, benefits, and difficulties were computed as the number of teachers whose responses received the code divided by the total number of teachers. Percentages for the subcategories of benefits and difficulties were calculated by dividing the number of teachers with the subcategory code by the number of teachers who mentioned anything within the broader category

teachers expected that the game would allow students to practice thinking critically through consideration of conflicting messages and viewpoints (Fani, 2011).

Students' views. We also assessed the views of students $(\mathrm{N}=134 ; 50 \%$ female, $48.5 \%$ male, $1.5 \%$ not reported) enrolled at two middle schools $(\mathrm{n}=38$ and $\mathrm{n}=34)$ and two high schools $(n=21$ and $n=39)$ in the Midwest. (One group of middle school students was part of a high science ability program.) Students were introduced to the game, divided into groups of 4 to 7 , and instructed to play the game. Afterwards, students completed a brief questionnaire that as- sessed their impressions of the game. Their responses are summarized in Table 2.

The majority of students (91\%) not only enjoyed the game but reported that the game resulted in thinking about genetics and ethics (88\%) as well as engagement and critical thinking (74\%). Contrary to the anticipated difficulties, students generally did not experience hurt feelings nor did they seem to find the game difficult to play; few found the game to be difficult $(8 \%)$ or offensive $(11 \%)$. Students who considered the game enjoyable were more likely to experience the benefits of the game (thinking about genetics and ethics as well as engagement and critical thinking) and were less likely to find the game difficult or offensive.

\section{CONCLUSIONS}

Overall, experiences using Luck of the Draw have been very positive. Although some teachers anticipated that the game might be difficult or offensive, most reported that they thought the game was enjoy-able and beneficial as did most students. Nevertheless, teachers should consider the potential for controversy and be prepared to manage student discussions, presenting issues in ways that maintain an appropriate level of controversy or disagreement. Contradicting viewpoints need not be undesirable; rather, the expression of different viewpoints provides an opportunity for students to practice critical thinking skills, to realize that people often vary greatly in social and cultural values that they may take for granted, and to learn to express their view-points in appropriate ways.

Science proficiency, interest in science careers, and public support for science have declined at a time when the need for experts in, and support for, science may be greatest. New methods to promote interest in science and critical thinking are sorely needed. The Luck of the Draw card game, in the three settings described here did engender discussion re-lated to desirability of different traits, the prospect of engineering offspring with particular traits, and the benefits or costs to society for these choices. Of course the levels of discourse varied from teachers to high and middle school teachers, yet engagement in the game was apparent in all groups. Future studies will be aimed at devising appropriate curricula at both middle and high school levels to test genetics engagement, knowledge, and critical thinking skills.

\section{ASSOCIATED CONTENT}

Supplemental information is available. Please contact the authors if you would like to receive copies of the cards. 
Table 2. Mean responses of middle and high school students by category and item

\begin{tabular}{|c|c|c|c|}
\hline Variable Name & $\mathbf{M}$ & SD & $\alpha$ \\
\hline Engagement/critical thinking & 3.5 & 0.89 & 0.86 \\
\hline This game makes me want to learn more about genetics & 3.76 & 1.03 & \\
\hline This game makes me want to learn more about ethics & 3.56 & 1.16 & \\
\hline I would like to discuss genetics with my friends and/or family & 2.97 & 1.15 & \\
\hline I would like to discuss ethics with my friends and/or family & 2.9 & 1.27 & \\
\hline This game caused me to think more about why I value the traits I do & 3.83 & 1.24 & \\
\hline This game caused me to wonder why some traits are valued more than others & 3.95 & 1.09 & \\
\hline Offended & 1.66 & 1.01 & 0.8 \\
\hline My feelings were hurt by some of the things that were said in the discussions & 1.61 & 1.12 & \\
\hline Other group members' feelings were hurt by some of the things that were said in the discussion & 1.7 & 1.09 & \\
\hline Difficulty & 1.72 & 0.9 & 0.65 \\
\hline It was hard to understand the directions to this game & 1.97 & 1.2 & \\
\hline This game was too difficult & 1.47 & 0.85 & \\
\hline Think Genetics/Ethics & 3.72 & 0.79 & 0.66 \\
\hline How much did this game get you to think about ethics? & 3.71 & 1.06 & \\
\hline How much did this game get you to think about genetic engineering? & 3.9 & 1.13 & \\
\hline How much did this game get you to think about genetic testing? & 3.36 & 1.14 & \\
\hline How much did this game get you to think about cultural values about genetic traits? & 3.62 & 1.15 & \\
\hline Enjoyed Playing Game & 4.15 & 0.77 & 0.83 \\
\hline This activity was fun to do & 4.41 & 0.82 & \\
\hline I was interested in this game & 4.35 & 0.86 & \\
\hline I wish we could have spent more time on this activity & 3.8 & 1.09 & \\
\hline I enjoyed the discussion we had while playing this game & 4.03 & 1.01 & \\
\hline
\end{tabular}

Note. Sample size varied from 131 to 134. Response options ranged from 1 ("strongly disagree"/"not at all”) to 5 ("strongly agree"/"a lot"). $\alpha=$ Cronbach's alpha, a measure of reliability.

\section{AUTHOR INFORMATION Corresponding Author}

Maurice Godfrey, Ph.D. 985450 Nebraska Medical Center, University of Nebraska Medical Center, Omaha, NE 68198-5450 Phone (402) 559-6689; email mgodfrey@ unmc.edu

\section{Author Contributions}

The manuscript was written through contributions of all authors. All authors have given approval to the final version of the manuscript.

\section{FUNDING SOURCES}

This project was supported by the National Center for Research Resources and the Division of Program Coordination, Planning, and Strategic Initiatives of the National Institutes of Health through Grant Number OD021898 (MG) and an
American Society of Human Genetics - Genetics Education Research Program Award (MG).

\section{ACKNOWLEDGMENTS}

We wish to thank Toby Schonfeld, Ph.D., who along with Rebecca Anderson and Andrew Jameton developed the Luck of the Draw game.

\section{REFERENCES}

Alden, L. (2005). Birka: A trading game for economics students. Social Studies, 96, 178-183.

Annetta, L. A., Cheng, M., and Holmes, S. (2010). Assessing twenty-first century skills through a teacher created video game for high school biology students. Research in Science and Technological Education, 28, 101-114. 
Derting, T.L., and Ebert-May, D. (2010). Learner-centered inquiry in undergraduate biology: Positive relationships with longterm student achievement. CBE-Life Sciences Education, 9, 462-472. doi: 10.1187/cbe.10-02-0011

Fani, T. (2011, June). Overcoming barriers to teaching critical thinking. Paper presented at Pixel Online International Conference on the Future of Education, Florence, Italy. Paper retrieved from http://www.pixel-online.net/edu_future/acceptedabstracts.php

Knight, J.K., and Wood, W.B. (2005). Teaching more by lecturing less. Cell Biology Education, 4, 298-310. doi: 10.1187/0506-0082

Price, J. F., Pimentel, D. S., McNeill, K. L., Barnett, M., and Strauss, E. (2011). Science in the 21st century: More than just the facts. The Science Teacher, 78, 36-41. 